IZA DP No. 9872

On the Interpretation of World Values Survey Trust Question: Global Expectations vs. Local Beliefs

Ritwik Banerjee

April 2016 


\title{
On the Interpretation of World Values Survey Trust Question: Global Expectations vs. Local Beliefs
}

\author{
Ritwik Banerjee \\ Aarhus University \\ and IZA
}
Discussion Paper No. 9872
April 2016

IZA
P.O. Box 7240
53072 Bonn
Germany

Phone: +49-228-3894-0

Fax: +49-228-3894-180

E-mail: iza@iza.org

\begin{abstract}
Any opinions expressed here are those of the author(s) and not those of IZA. Research published in this series may include views on policy, but the institute itself takes no institutional policy positions. The IZA research network is committed to the IZA Guiding Principles of Research Integrity.

The Institute for the Study of Labor (IZA) in Bonn is a local and virtual international research center and a place of communication between science, politics and business. IZA is an independent nonprofit organization supported by Deutsche Post Foundation. The center is associated with the University of Bonn and offers a stimulating research environment through its international network, workshops and conferences, data service, project support, research visits and doctoral program. IZA engages in (i) original and internationally competitive research in all fields of labor economics, (ii) development of policy concepts, and (iii) dissemination of research results and concepts to the interested public.
\end{abstract}

IZA Discussion Papers often represent preliminary work and are circulated to encourage discussion. Citation of such a paper should account for its provisional character. A revised version may be available directly from the author. 


\section{ABSTRACT}

\section{On the Interpretation of World Values Survey Trust Question: Global Expectations vs. Local Beliefs*}

How should we interpret the World Values Survey (WVS) trust question? We conduct an experiment in India, a low trust country, to correlate the WVS trust question with trust decisions in an incentivized Trust Game. Evidence supports findings from one strand of the fractured literature - the WVS trust question captures expectations about others' trustworthiness, though not always. We show that WVS trust question correlates with globally determined stable expectations but does not correlate with short term locally determined fluctuations in beliefs about trustworthiness. One implication of our study is that survey based methods may not be used to measure contextualized beliefs.

JEL Classification: corruption, social capital, belief, trust games

Keywords: C91, C92, D03

Corresponding author:

Ritwik Banerjee

Department of Economics and Business

Aarhus University

Fuglesangs Allé 4

8210 Århus V

Denmark

E-mail: ritwikbanerjee@iimcal.ac.in

\footnotetext{
* I thank Alexander Koch, Nabanita Datta Gupta, Marco Piovesan, Klaus Abbink, Luigi Zingales, Marie Claire Villeval, Emma von Essen, seminar/conference participants at Aarhus University, IIM Calcutta, IIT Gandhinagar, IIM Ahmedabad, Winter School at DSE 2014 for their comments and suggestions. I also thank Sujoy Chakrabarty and Bibek Banerjee for making it possible for me to run the experiment and Manas Pathak for his research assistance. The experiment was funded with grants from Department of Economics and Business, Aarhus University.
} 


\section{Introduction}

Trust has been found to play an important role in determining economic activity. Higher levels of trust have been associated with higher levels of economic growth (Knack and Keefer, 1997), higher levels of financial development (Guiso et al., 2004, 2008), and greater international trade and investment (Guiso et al., 2009). Most of these cross country studies have relied on the response to the generalized trust question asked in the World Values Survey (WVS) or General Social Survey (GSS). The generalized trust question is the following: "Generally speaking, would you say that most people can be trusted or that you need to be very careful in dealing with people?" On the other hand the experimental literature, following Berg et al. (1995), has evolved in a different direction - this literature has focused on measuring trust and trustworthiness through incentivized experimental games. The classic experimental Trust Game mimics a situation where a sender decides whether or not to cooperate with the receiver. Cooperation makes sense for the sender only if her perceived chance that the receiver will reciprocate is high enough. Of course the receiver may or may not decide to reciprocate the sender. Interestingly, this mechanism elicits trust and trustworthiness behavior in a direct definitional sense while the WVS trust question relies more on respondent's interpretation of the question and her frame of reference.

Since nationally representative scale incentivized Trust Games are expensive, WVS trust question is a widely used trust measure. As both incentivized elicitation and survey based measure claim to measure trust, it has been a long standing project of economists to examine how the two measures correlate and even if they do, whether they measure the same behavioral primitive. However, past studies have been unable to find an unambiguous or even nearly conclusive evidence in this regard. (Fehr et al., 2003; Bellemare and Kroger, 2007) found that the response to WVS trust question is correlated with the sender's trust behavior in lab based experimental Trust Games but not with receiver's trustworthiness behavior. (Glaeser et al., 2000; Lazzarini et al., 2004), on the other hand, found that the WVS trust measure is correlated, not with trust, but with trustworthiness instead.

In an important study, Thöni et al. (2012) report that WVS-trust question is a proxy for cooperative preferences rather than beliefs about how cooperative people are. This is contradicted soon after by Sapienza et al. (2013), who make a significant contribution to this literature by showing that the survey response actually relates to neither trust nor trustworthiness but relates to a subject's belief about how trustworthy others are. They argue that the measure, that is most consistent with the definition of trust, is the belief component of the sender's behavior in the Trust Game and not the preference based component. According to them, it is this belief or expectation about how others behave which is well captured by the WVS trust question.

With this background of multifarious results in the literature, we aim to revisit this issue and understand what is it that the WVS trust question measures. If it does measure the belief about others' trustworthiness, then under which circumstance(s) does the claim that the WVS trust captures the belief based component of trust hold true and when does the relation fail? In 
particular, we ask, are the reference frame in which the WVS trust question is answered same as that under which incentivized trust decisions in laboratory Trust Games made? Does the WVS trust question capture the short term fluctuations in our beliefs?

A second aim of this study is to analyze this issue in a cultural context very different from all previous studies on this subject. Why is that important? Remember that World Values Survey is a global research project which aims to track "...Political and Sociocultural Change" through nationally representative survey in more than 100 countries over time. In other words, World Values Survey aims to be globally representative. In order to ensure global representativeness WVS does employ the necessary instrument, namely, a common questionnaire across the world. However, this is far from being sufficient. In order for the survey results to be consistent, comparable and globally representative, it is critical that the questions in WVS are interpreted in the same way by people everywhere. And this is far from obvious given the nature of the inquiry - that it is engaged with subjective opinions, values and beliefs. As an example, consider someone being ill. Queries about her illness may be considered invasion of privacy in some parts of the world while it may be interpreted as coming from genuine concern in some other. Social desirability bias may systematically vary across cultures as well, rendering responses across countries incomparable.

We design an experiment where we can measure trust, trustworthiness and also separately identify long term stable expectations and short term fluctuations in beliefs about how trustworthy others are. Then we elicit response to the WVS trust question to see if the latter is correlated which type of beliefs the WVS trust question correlates with. The way we induce a negative fluctuation in beliefs is by letting subjects go through a negative experience before they play a Trust Game - more specifically they go through an experience of having to give bribe in order to have what is rightfully theirs in a corruption game. Corruption have been studied through lab based experimental games in the past (see for example Cameron et al. (2009); Alatas et al. (2009)). In our between subject design, "Citizens" and "Public Officials" play a real effort harassment bribery game". A Citizen performs a task and earns a prize, if successful. However, a Public Official, may demand a bribe before the Citizen can have her prize which she may accept or reject. The negative experience of having to pay a bribe may lead people to believe that people are less trustworthy in a Trust Game that follows, relative to a standalone baseline Trust Game. Thus, a difference in beliefs between the baseline Trust Game and Trust Game preceded by a bribery game may be attributed to the negative experience of having to pay a bribe. The observed treatment effect in beliefs could be attributed to either bribe or the pure income effect of the bribe amount. In order to precisely pin down the source of the negative belief shock, we probe even further.

We construct a strategically identical but differently framed counterfactual where Participant A (analogous to the Citizen), upon successfully completing the task, earns the right to go to the second

\footnotetext{
${ }^{1}$ In a harassment bribery game a Citizen is entitled to a prize but a Public Official demands a bribe from the Citizen before he lets her have the prize. It mimics a situation where ordinary Citizens are entitled to government services such as passport or driver's license but have to either pay a bribe in order to obtain them or suffer inordinate procedural delays. Abbink et al. (2014) and ? study different aspects of harassment bribery game.
} 
stage of the game. At the second stage, Participant B (analogous to the Public Official) plays an Ultimatum Game with the same stake size as the prize in the bribery game, and decides how much to share with Participant A, which the latter can accept or reject. After subjects have gone through the experience of either the Bribery Game or the Ultimatum Game and have known the outcomes, we measure their trust behavior in a standard Trust Game. Thus, in all our experiment comprises of three treatments, to which subjects are randomly assigned - Bribery Game treatment, Ultimatum Game treatment and the baseline Trust Game. Each treatment is followed by a short survey where subjects are asked to respond to the WVS trust question, among other things. The logic of the design wrests on a finding by?, who show that the difference in behavior between the Bribery Game and its strategically identical counterpart - the Ultimatum Game can be partly attributed to the difference in social norm governing the two frames. Specifically, a bribe demand is considered inappropriate from a moral standpoint but the same amount when retained in an ultimatum game may be considered appropriate. As a result a bribe demand in the Bribery Game may induce a negative shock in the belief about how trustworthy people are whereas the same amount, when retained in the Ultimatum Game, may not.

Our findings suggest that WVS trust response is not correlated with the sending decisions in the Trust Game. Instead, it is correlated with the expectation about how trustworthy others are. Deeper probe reveals that in fact beliefs about trustworthiness do suffer a negative shock in the Bribery Game treatment relative to the Ultimatum Game and the baseline trust treatment. The centerpiece of our results is a consequence of that - the correlation between WVS trust and expectation about trustworthiness holds for Participant As and baseline subjects, but not for the Citizens. Since the expectation of the Citizens about the trustworthiness of the matched partners is lower than that of the Participant As and baseline subjects, our main result suggests that WVS trust response does well in capturing stable expectations about how others in general behave, however, it is a bad proxy for locally determined short term fluctuations in beliefs. Our preferred interpretation of this result is that while the reference frame of beliefs, elicited through Trust Games, is more immediate, subjects view the WVS trust question in a longer term pan-societal context.

So should we rely on survey based measures as a proxy for beliefs? Our results show that the answer to this question is yes only if we are interested in measuring long run stable beliefs and not its short run fluctuations. Thus, laboratory experiments, which are more geared towards generating psycho-emotional triggers, may not use survey based methods such as in WVS to measure beliefs. This is the main contribution of our paper. Second, we demonstrate the need to see stable beliefs as different from its short run fluctuations. The stable beliefs are conceptually closer to the sense in which beliefs are understood in a rational expectation framework. They are formed by aggregation of our experiences in multiple domains of our life and hence may as well be called "global expectations." To the contrary, the short run fluctuations in beliefs are shaped by local environments and immediate experiences. These fluctuations are more likely to converge 
to the stable steady state over time and hence may be called "local beliefs". While differentiating between global expectations and local beliefs, we show that measuring these two concepts require different set of instruments. An interesting implication of our result is people do not seem to generalize negative experiences to population at large immediately.

Third, the literature on framing shows that framing has an important effect on how people behave. Our paper contributes to that literature by demonstrating that not only does framing affects behavior, but it also has a spillover effect on beliefs in an unrelated domain. Finally, our study is directionally consistent with results from Sapienza et al. (2013) in a socio-cultural environment very different from theirs, indicating that respondents interpret the WVS trust question in a similar way across the two cultures. We believe this is only a beginning of a series of study which needs to be conducted to understand how questions about values, opinions and beliefs are interpreted across cultural regions. Only then will we be able to ensure that responses to such queries are truly globally representative.

The rest of the paper is organized as follows: Section 2 lays out the experimental design and briefly sketches the important survey questions. Section 3 presents the broad results and the mechanisms behind the results and Section 4 discusses the results and offers the concluding remarks.

\section{Experimental Design}

One way to induce a negative shock to the beliefs of subjects is by letting them go through a negative experience. We simulate such a situation by letting subjects play a harassment bribery game (BG) before playing a Trust Game. Beliefs about trustworthiness following BG may then be contrasted to beliefs about trustworthiness in a baseline Trust Game (i.e. a Trust Game not preceded by a bribery game) and the difference may be interpreted as a shock to expectations about others' trustworthiness. However, source of such a shock can be interpreted as either a result of bribe extraction or simply the negative income effect. In order to tease apart the origin of the shock, we design a counterfactual of the bribery game treatment, which is strategically identical to the bribery game but is differently framed. It turns out that this strategically identical but differently framed game is a variant of what is standardly known as an Ultimatum Game (UG). The Bribery Game and the Ultimatum Game differ from each other on two aspects - one, the former uses a loaded language (e.g. Citizen, Public Official, bribe etc.) while the latter uses a neutral language (e.g. Participant A, Participant B and transfer); two, in terms of the difference in the sense of entitlement among the subjects induced by a difference in the endowment (see Banerjee (2016) for a detailed analysis of the difference in two frames). Thus, the three treatments in our experiment are - Trust Game preceded by BG, Trust Game preceded by UG and baseline Trust Game. Each subject then answers a survey questionnaire which includes the World Values Survey trust question, among others. 
The premise of the experimental design is that a bribe demand may be considered unfair in BG but the same amount in UG may be considered fair. Thus, the two frames are expected to trigger different psychological responses despite being identical in strategic terms. In particular, we expect that immorality of bribe demand will lead to a negative shock to beliefs about how trustworthy a matched partner is, relative to the ultimatum game and the baseline Trust Game. This approach of examining the behavioral response by inducing psychological triggers has been adopted in the past; for example Burnham et al. (2000) study how framing the matched partner as friend or foe affects behavior, Rosaz and Villeval (2012) andMaggian and Villeval (2015) use it in the context of lying, Buser and Dreber (2013) study the effect of competition on cooperation and Drouvelis et al. (2010) study prime cooperation in social dilemma games.

\subsection{Bribery Game and Ultimatum Game}

The Bribery Game is illustrated in Figure 1(a). A Citizen (C) is given ten minutes, within which she has to complete a real effort task ${ }^{2}$. This gets her a prize winning code which entitles her to a prize of 400 Mohars $^{3}$ (M400). If she is unable to reach the code within the stipulated time then she only earns the participation fee of M200. However, even if the Citizen does get the prize winning code a matched Public Official (PO) may demand a bribe of amount bbefore he lets her have the entitled prize. Notice that any bribe that the PO demands is an extract from the Citizen's entitlement, which in this case is $\mathbf{M} 400$. We let the bribe amount take the following values - 0, 100, 200, 300, 400 Mohars. Upon being asked to pay a bribe, a Citizen may either accept it or reject it. She earns $\mathbf{M}(200+400-b)$ if she accepts the bribe demand and only M200 if she rejects it. The PO on the other hand earns the participation fee of M200 and a salary of M400 for approving the Citizen's entitlement. Additionally, he gets the bribe amount demanded if he does demand a bribe and it is accepted i.e. his total earning in this case is $\mathbf{M}(200+400+b)$. If the Citizen rejects the bribe demand then of he earns only the M600.

This is a one shot game and the real effort task is calibrated in a way such that a Citizen is more likely to complete the task and get the prize winning code. However, making the Citizens perform the real effort task was crucial to induce a sense of harassment among them. This version of the Bribery Game closely mimics the often encountered situations in developing countries where a Citizen is entitled to a passport or a driving license but still has to pay a bribe to get it. Such bribe extractions are typically considered unfair since it means being forced to give up resources which

\footnotetext{
${ }^{2}$ We employ a computer based task - Citizens have to count the number of occurrences of the letter "A" in five different panels, each with a random sequence of letters A, B, C, D, E. The panels appear one after the other and a subject is not be able to proceed unless she correctly counts the number of As in the incumbent sequence. The prize winning code is mentioned at the end of the fifth panel. The task ensures that a Public Official does not need to grade the Citizen's answers, but is still able to figure out, whether she has been able to complete the task or not by looking at the prize winning code in her response sheet.

${ }^{3}$ Mohar or gold coins were used as currency in medieval India. It was used as a currency in our experimental set up.
} 
are rightfully one's own. A design feature which is used to exacerbate the sense of unfairness is that the lower bound of PO's earning is also the upper bound of C's earnings. The bribe amount only increases PO's already high earnings. Furthermore, this ensures that no demand can be interpreted as being motivated by inequality aversion. We expect that a consequence of such bribe extraction will be to reduce people's expectations about how fair others are. Hence, our decision to implement this design.

Figure 1(b) lays out the Ultimatum Game and it is isomorphic to the Bribery Game. There are, however, two main differences: First, UG uses a neutral language frame (e.g. Participant A, Participant B and transfer) while BG uses a loaded language frame (Citizens, Public Officials and bribe); second, while a Citizens in BG is entitled to a prize once she completes the task, Participant A in UG only qualifies to the next round of the game in which Participant B play an ultimatum game with her with the same stake size as the prize in BG. Suppose P-B retains $x$ with him then $\mathrm{P}-\mathrm{A}$ receives $\mathrm{M} 400-x$. The payoffs in the $\mathrm{UG}$ are the following: If $\mathrm{P}-\mathrm{A}$ accepts (rejects) the offer then she gets M200+400-x (M200) and P-B earns M 200+400+x (M600). Clearly, the UG is a strategically identical but differently framed counterfactual to BG with markedly different sense of entitlements. As a result, we expect UG to trigger different psychological response than BG.

Figure 1: Bribery Game (BG) and Ultimatum Game (UG)

\section{(a) BG}

Citizen performs a task, needs to complete it in 10 minutes

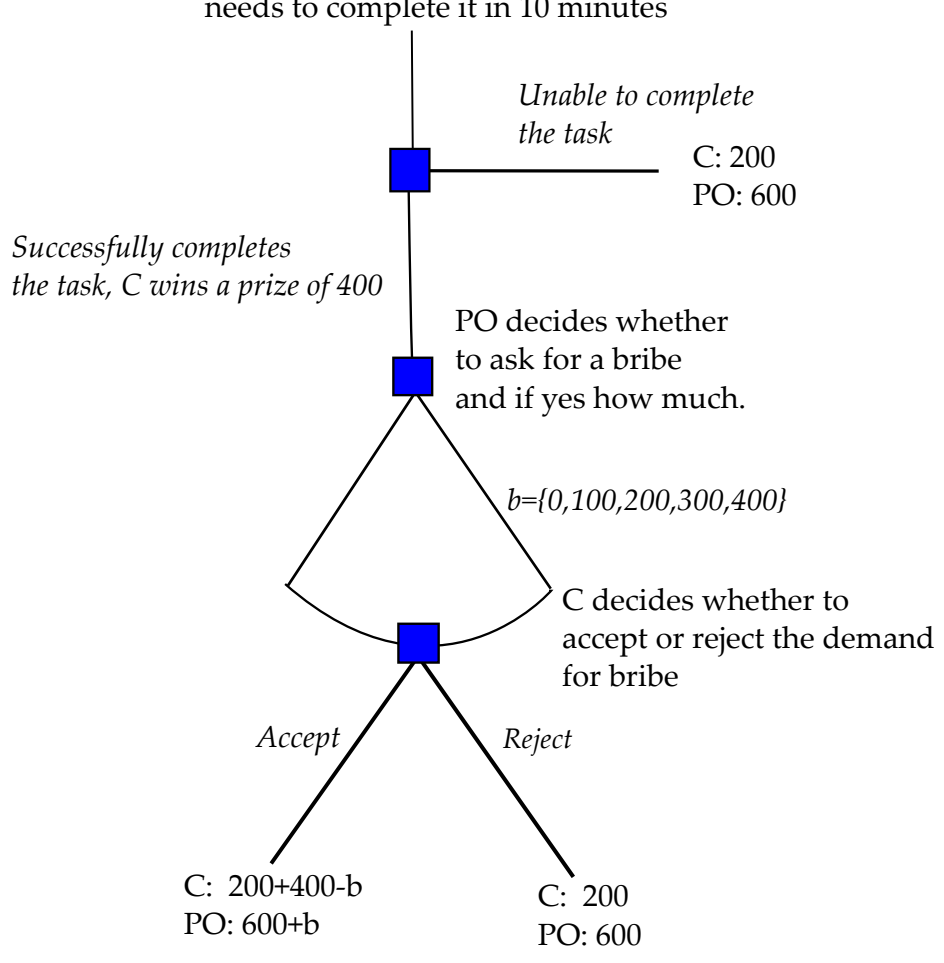

(b) UG

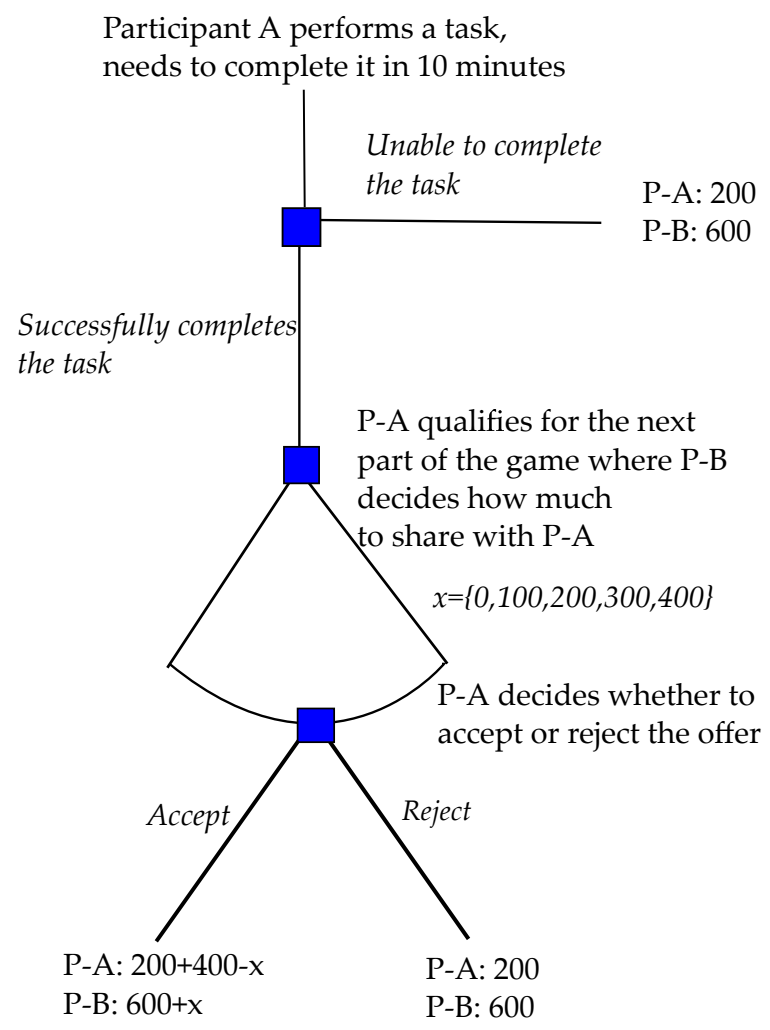




\subsection{Trust Game}

The Trust Game, which follows the BG and UG treatments, is a close variant of the Trust Game proposed by Berg et al. (1995). A sender has M400 and is matched to a receiver. The sender sends an amount $s$ to the receiver where $s$ can take values from the set $\{0,50,100, \ldots 400\}$. The amount is multiplied by 3 before reaching the receiver. The receiver then sends back an amount to the sender. Thus, the amount the receiver sends back (say $r$ ) takes a value from the set $\{0,50, \ldots$ 3s . The final payoff of the sender is $\mathbf{M} 400-s+r$ whereas that of the receiver is $\mathbf{M} 3 s-r$. The literature interprets $s$ as a measure of trust and $r$ as a measure of trustworthiness.

Subjects make their decisions both as a sender and a receiver through a strategy elicitation method and role uncertainty is enforced. First, subjects make their decision as senders and decide how much to transfer to the receivers. Second, they reveal how much they believe the receiver will return for each possible amount sent. This helps us obtain off the equilibrium path responses too. They are rewarded $\mathbf{M 1 0 0}$, if their belief in a randomly chosen trust category matches the actual outcome. Third, subjects make their decisions as receivers, where they indicate how much they will have sent back for every possible amount, which they could have possibly received.

\subsection{Survey Data}

At the end, the subjects write an exit survey, which is designed to acquire demographic data and measure various personality traits. Our main survey measure of trust came from the standard trust question of the World Values Survey : "Generally speaking, would you say that most people can be trusted or that you need to be very careful in dealing with people?" Sapienza et al. (2013) had administered this question, as a part of the survey, one week before the actual experiment was conducted. In our case, it was important that this question was asked after the experiment was conducted in order to allow for the possibility that experimental behavior could influence its response. Table A2 in the Appendix gives the summary statistics of the responses to this question. In our sample, $32 \%$ of the students said that most people can be trusted. The corresponding figure in the nationally representative data from all the waves of the World Values Survey in India is 35\%.

The survey included two additional measures of trust. The first one, also taken from WVS, was: "Do you think most people would try to take advantage of you if they got the chance, or would they try to be fair?" The second question was, "Suppose you left your wallet with Rs. 500 in the Metro. On a scale of 1 to 10, how much do you think are the chances that you will get it back?" The response to these questions have not been included in the analysis below, but the pairwise correlations and summary statistics have been reported in Table A2 in the Appendix.

Besides the trust questions, we also obtain risk preference by asking survey based questions. These questions have been used to measure risk in large scale behavioral surveys such as the German Socio-Economic Panel (SOEP). For example, one question directly asks subjects to make 
an assessment about their general willingness to take risks on a scale of 1 to 10: "How willing are you to take risks, in general?" Though the survey also includes other questions about risk attitudes in specific dimensions such as financial matters, car driving, health and career, the analysis below relies on the general measure of risk, since Dohmen et al. (2011) found that the general measure is the best predictor of risky behavior elicited through an experiment. The descriptive statistics of the variables used in the analysis are presented in Table A1 in the Appendix.

\subsection{Experiment Procedure}

The experiment was conducted in Delhi in January 2014. Subjects were recruited from a private management training institute. 218 students participated with 45 pairs in the UG treatment, 46 pairs in the BG treatment and another 36 pairs in the baseline treatment. Subjects were randomly assigned in the $\mathrm{UG}$ and $\mathrm{BG}$ treatment and then were randomly assigned roles. Different roles in each treatment were allocated different rooms. Citizens/P-As first completed the computer based task and mentioned the prize winning code in the response sheet which was then transferred to the POs/P-Bs. They put down their demand decision on the response sheets, and these were then transferred back to the Citizens/P-As for their acceptance decisions. Citizens/P-A were then informed of their final earnings. It was important that we informed them how much less they were being paid than what they deserved, in order to reinforce in them the sense of unfairness.

The Trust Game followed the BG/UG games. Subjects played both the roles of sender and receiver but their earnings from this part was determined by randomly picking one of the roles. The final earning from the experiment was determined by randomly picking one of the two parts. The sessions lasted for one and a half hour. The instructions were read out in English. All payoffs for this experiment were stated in terms of a fictitious currency called Mohar. At the end of the experiment, participants exchanged their earnings for Rupees at the rate of 100 Mohars = Rs. 50 . The earnings ranged from Rs. 100 to Rs. 700 with an average of Rs. 252 ( 10 PPP USD ).

\section{Results}

\subsection{Behavior in BG, UG and Trust Game}

Since the focus of this paper is to examine how WVS trust question correlates with trust, trustworthiness and expectations about trustworthiness, we will only briefly state the results of the bribery game, ultimatum game and the Trust Game. A detailed exposition of the mechanisms behind the framing effects between BG and UG and their differential effects on the Trust Game may be found in Banerjee (2015).

Despite being strategically identical, subjects behaved very differently in the BG and UG games. $19 \%$ of the subjects demanded no bribe in BG whereas everyone in the UG demanded a positive 
amount $\left(\chi^{2}\right.$ test, $p$-value $\left.=0.00\right)$. The full sample mean amount demanded in BG is M182.6 while that in $\mathrm{UG}$ is $\mathrm{M} 268.9$ ( $t$-test, $p$-value<0.001). If we restrict our attention to the non-zero sample then the average amount demanded in BG and UG are M245.9 and M268.8 ( $t$-test, $p$-value $=0.02$ ). Clearly, BG and UG have triggered different behavioral responses in $\mathrm{PO} / \mathrm{P}-\mathrm{B}$. $\mathrm{C} / \mathrm{P}-\mathrm{A}$ too have perceived the two frames very differently - for a given amount, a greater proportion of Cs in BG choose reject than $\mathrm{P}-\mathrm{As}$ in $\mathrm{UG}$, indicating that a demand in the former is considered more unfair than in the latter. Table 1 provides a summary of the differences and shows that the difference is statistically significant for the amounts 200 and 300 ( $\chi^{2}$ test, $p$-value $\left.<0.001\right)$.

It turns out that not only have the two frames triggered different reactions from the subjects, but they have induced different behavioral spillovers on the the Trust Game too. The full sample mean amount sent by Citizens in the role of the sender is M205.4 while that for P-A is M261.1 $(t$-test, $p$-value $=0.04)$. The corresponding figures for the restricted (i.e. non-zero) sample are M230.5 and M273.3 ( $t$-test, $p$-value=0.08). These results indicate that Citizens in BG tend to trust less than Participant As in UG. It is clear from 1 that the baseline trust, which in some sense captures the native distribution of trust, appears to be statistically indistinguishable from the trust behavior in the UG treatment but not that in the BG treatment. Thus, we could as well have used the baseline trust measure as the counterfactual to the BG.

To study trustworthiness, we convert the amount returned by a receiver to a Return Ratio (RR) where $R R=$ Amount Returned/Amount Received. RRs averaged over all the possible trust categories give our trustworthiness measure for a given person. We do not find any difference in this measure of trustworthiness between $\mathrm{C}$ and $\mathrm{P}-\mathrm{A}$. The average $\mathrm{RR}$ for all the subjects are plotted for each trust category in 2(b). The close co-movement of the RRs and the fact that they are statistically insignificant between BG, UG and baseline treatments for all the trust categories show that trustworthiness has remained stable across the treatments. 
Table 1: Treatment Effects in Bribery Game, Ultimatum Game and Trust Game

\begin{tabular}{|c|c|c|c|c|c|c|}
\hline Variable Names $^{a}$ & BG & UG & $\operatorname{Diff}(1)^{b}$ & & & \\
\hline Percent who asked for bribe/ultim & 81 & 100 & $19 \quad(<0.01)$ & & & \\
\hline Full Sample Bribe/ultim amount & 182.6 & 268.8 & $71.1(<0.01)$ & & & \\
\hline Restricted Sample Bribe/ultim amount & 245.9 & 268.8 & $22.9(0.02)$ & & & \\
\hline Percent accepted when amount $=100$ & 93.5 & 97.8 & $4.3 \quad(0.31)$ & & & \\
\hline Percent accepted when amount $=200$ & 80.4 & 97.8 & $17.4(<0.01)$ & & & \\
\hline Percent accepted when amount $=300$ & 73.3 & 41.3 & $32.0(<0.01)$ & & & \\
\hline \multirow[t]{2}{*}{ Percent accepted when amount $=400$} & 17.8 & 10.8 & $7 \quad(0.34)$ & & & \\
\hline & BG & $\mathrm{UG}$ & Baseline & $\operatorname{Diff}(1)$ & $\operatorname{Diff}(2)^{c}$ & $\operatorname{Diff}(3)^{d}$ \\
\hline Percent decided to trust & 89.1 & 95.6 & 94.4 & $6.5(0.25)$ & $5.31(0.39)$ & $1.2(0.82)$ \\
\hline Full Sample Trust Amount & 205.4 & 261.1 & 256.9 & $55.7(0.04)$ & $51.5(0.06)$ & $26.8(0.88)$ \\
\hline Restricted Sample Trust Amount & 230.5 & 273.3 & 272.1 & $42.8(0.08)$ & $88.8(0.08)$ & $1.2(0.96)$ \\
\hline
\end{tabular}

\footnotetext{
${ }^{a}$ The restricted sample comprises of only those who demanded a non-zero amount in the BG, UG or the Trust Game.

${ }^{b}$ Diff(1) denotes the difference between UG and BG. The numbers in the brackets represent $p$-values. For comparing proportions in the table, $p$-values from $\chi^{2}$ test of equality of proportions are reported. For comparison of sample mean, $p$-values from $t$-test are reported.

${ }^{c}$ Diff(2) denotes the difference between BG and Baseline.

${ }^{d}$ Diff(3) denotes the difference between UG and Baseline.
}

To examine whether the treatments had differential effects on beliefs, we now focus our attention on beliefs about others' trustworthiness. Remember that we had collected this data in a strategy method as well - hence, we have belief about trustworthiness for each trust category as reported by each person. To arrive at a sensible measure we normalize the beliefs to Expected Return on Trust (ERoT) where ERoT $=($ Expected Return for atrustlevel - Trustlevel $) /$ Trustlevel. In 2(a) we plot mean ERoT for Citizens, P-As and baseline subjects for all trust categories using the full strategy vector. The data reveals that the expected return is significantly less for Citizens than for P-As and the baseline subjects, particularly for lower levels of trust. This indicates that Citizens have suffered a negative shock in their beliefs about how trustworthy their matched partners are. This belief is significantly lower than beliefs of Participant A or baseline subjects. The data also reveals that subjects have largely negative expectations about their matched partners' trustworthiness when the full strategy vector is considered. Of course the expectations corresponding to actual response is greater than zero and thus consistent (not reported). 
Figure 2: Expected Return on Trust

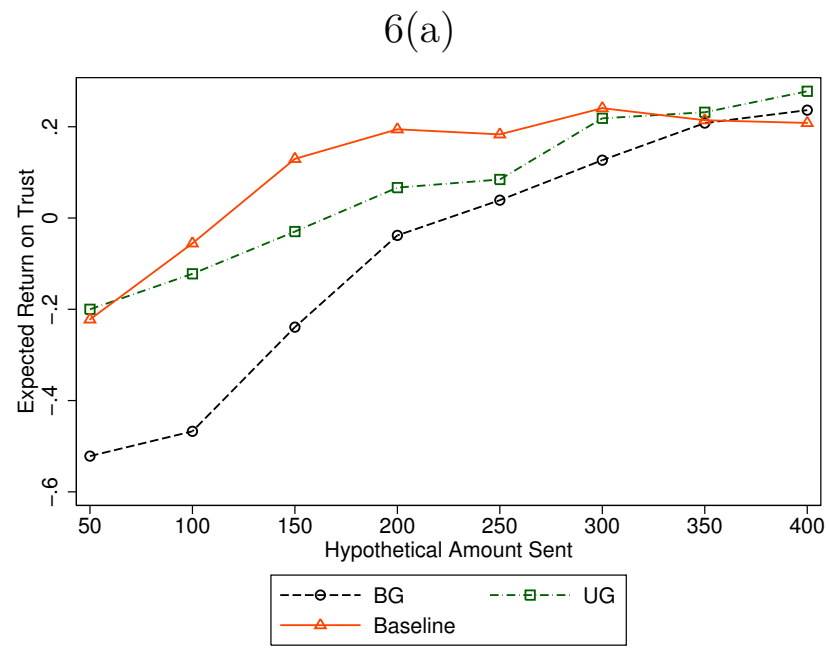

Note: The panel plots the average Expected Return on Trust for full strategy vector data of subjects in baseline and those playing Citizen and Participant A in BG and UG, respectively. $6(\mathrm{~b})$

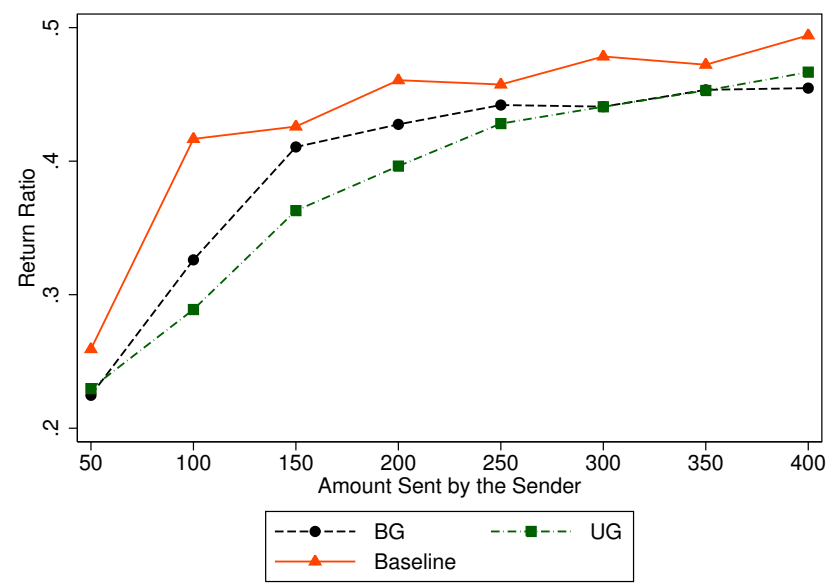

Note: The above figure plots the average return ratio (i.e. trustworthiness), for all possible bribe amounts, of subjects in baseline and those playing Citizen and Participant A in BG and UG, respectively.

\subsection{Analysis of actual behavior, beliefs and WVS-trust}

Panel 2(A) in Table 2 reports the probit regression of the WVS trust on trustworthiness. Col (1) - (8), which report the marginal effects, indicate that trustworthiness do predict WVS trust for higher amounts of trust. The marginal effects are economically significant for higher amounts of trust, though statistical significance remains weak. A $10 \%$ increase in trustworthiness increases the conditional probability that WVS trust takes value one by 4.3 to 4.8 ppts for 300 or higher amount sent. This seemingly supports results found in past studies such as by Lazzarini et al. (2004) and Glaeser et al. (2000), who interpret WVS trust as measuring trustworthiness. However, this interpretation is incorrect. Col (1) - (8) in Panel 2(B) report the marginal effects of probit estimation of EVS-trust on trustworthiness for each trust category after controlling for the expected 
return on trust. Once ERoT is included, we notice that WVS trust is actually predicted by ERoT and not the trustworthiness - a 10\% increase in ERoT increases the probability that WVS trust takes a value 1 by 2.1 to 2.8 percentage points (ppts). The relation only holds for trust levels of 150 and higher. This implies that subjects' responses to WVS trust are not independently associated with their trustworthiness. Instead, they are associated with the expectations that subjects form about their matched receivers' responses. In other words, WVS trust captures the subjects' expectations about how trustworthy a matched partner is, when the stakes are high enough. Panel 2(C) estimates a probit model of WVS trust on ERoT and risk preference as measured by the generalized risk question. Clearly, the WVS trust response is predicted not only by the ERoT, response to the risk question too turns out to be a consistent and economically and statistically significant predictor of WVS-trust. Why do trustworthiness correlate with expectations about how others will behave? Our view is that this is a homogenous subject pool and

We now take a closer look at how WVS trust captures the belief component of the senders belonging to different treatment groups. In particular, remember that $\mathrm{C}$ had a very different belief profile than P-A and baseline subjects. Our main focus now is to understand to what extent the WVS trust question captures the beliefs of each of the treatment subgroups. Hence, we restrict our attention to the responses from Citizens, Participant As and baseline subjects in the analysis that follows. In Table 3, where we adopt the same empirical specification as in Panel 2(C) of Table 2, we report the probit regression results of WVS trust on Expected Return on Trust for all possible amounts sent and the risk preference. Panel 3(A) reports the results for Citizens, Participant As and baseline subjects, panel 3(B) for P-A and baseline, panel 3(C) for P-A only and panel 3(D) for Citizens only. It turns out that the coefficient of ERoT is statistically significant in Panel 3(A), $3(\mathrm{~B})$ and $3(\mathrm{C})$. Besides, the coefficients are economically significant too - a $10 \%$ increase in ERoT leads to a 2.0 ppts to 3.4 ppts increase in the odds that a subject responds by saying that most people can be trusted, as reported in in Panel 3(A). The corresponding figures in Panel 3(B) are 2.4 ppts to 6.8 ppts and in Panel 3(C) are 3.1 ppts to 8.8 ppts. As the trust level increases, the strength of the association between expectations about others' trustworthiness and WVS trust increase, so do the statistical significance. Also, it increasingly better explains the variation in WVS trust as is indicated by the increase in Pseudo-R $2^{4}$ as the hypothetical amount sent increases. Also note that in all the panels the risk preference measure consistently predicts WVS-trust. However, this pattern does not hold in Panel 3(D) which restricts the sample to the Citizens from BG. While the risk measure continues to predict WVS trust response, ERoT does not. The magnitude of the marginal effects remain small even for higher levels of trust and the standard errors are large. Clearly, WVS trust has failed to capture beliefs about others' trustworthiness in so far as the Citizens are concerned. A snapshot of these findings can be found in Figure 3.

\footnotetext{
${ }^{4}$ It is well known that Pseudo-R2 cannot be interpreted as a R2, but the Pseudo-R2 still has a consistent meaning when compared to another Pseudo-R2 predicting the same outcome in the same data. In such a situation, a comparison of Pseudo-R2 indicates which model better predicts the outcome.
} 
The same pattern is revealed when the data is analyzed through another angle. Now we restrict the data to BG and $\mathrm{UG}$ and report the probit regression estimates of WVS trust on ERoT, treatment dummy and their interaction in Table 4 in Appendix 1. ERoT is a significant predictor of WVS trust - a 10\% increase in ERoT increases the odds that WVS trust will take value 1 by 2.8 to 10 ppts. However, the negative coefficients for interaction term, specially corresponding to higher amounts of trust, reflect that the marginal effect of ERoT on WVS trust is significantly higher for UG than for BG. In other words, response from ERoT to the odds that WVS trust takes a value 1 is significantly higher for P-As in UG than for Cs in BG, for sufficiently high trust levels.

Why is it that the response to WVS trust question is predicted by ERoT for the P-As and the baseline subjects but not for the Cs? Recall from Figure 2 that ERoT is lower for Citizens than for P-As and baseline subjects. Table in the Appendix uses belief data for each trust category separately and Table pools the data together to essentially arrive at the same conclusion - beliefs systematically differ across treatments. In particular, beliefs about how trustworthy someone is

suffers a negative shock in BG relative to UG and baseline treatments. If we believe that the baseline treatment captures the native belief distribution then beliefs in UG closely follow that native distribution whereas those in BG does not. Clearly, the negative belief shock in BG can be attributed to the negative experience of having to pay a bribe in BG. The fact that WVS trust correlates with the beliefs in $\mathrm{UG}$ and baseline treatment but not in BG treatment indicates that conceptually there is a need to separate stable expectations from short term fluctuations in beliefs. The former is globally determined from the aggregation of experiences whereas the latter is a result of immediate experiences and is inherently unstable. The WVS trust does well in capturing long run stable expectations but not in measuring its short term fluctuations.

\section{Discussion and Conclusion}

World Values Survey is a unique data source in the sense that it aims to measure a gamut of otherwise unobservable characteristics through globally comparable and nationally representative surveys in over 100 countries. The operative phrase here is "unobservable characteristics", implying that the focus is one measuring subjective perceptions, opinions and values. For cross country comparability to be valid it is critical that respondents interpret and react to the questions used in the World Values Survey in the same way across different socio-cultural regions across the world. This is particularly of first order importance given the nature of the inquiry and its aim at measuring subjective perceptions, opinions and values. However, there is surprisingly little in the literature with regard to establishing a correspondence between WVS responses and incentivized elicitation of behavior beyond Western subject pools. In fact to the best of our knowledge ours is the first study in this direction.

This study was inspired in part by Sapienza et al. (2013) - they found that WVS trust question measured expectation about others' trustworthiness. Our study was designed with two important 
Figure 3: Regression Coefficients from Table 3
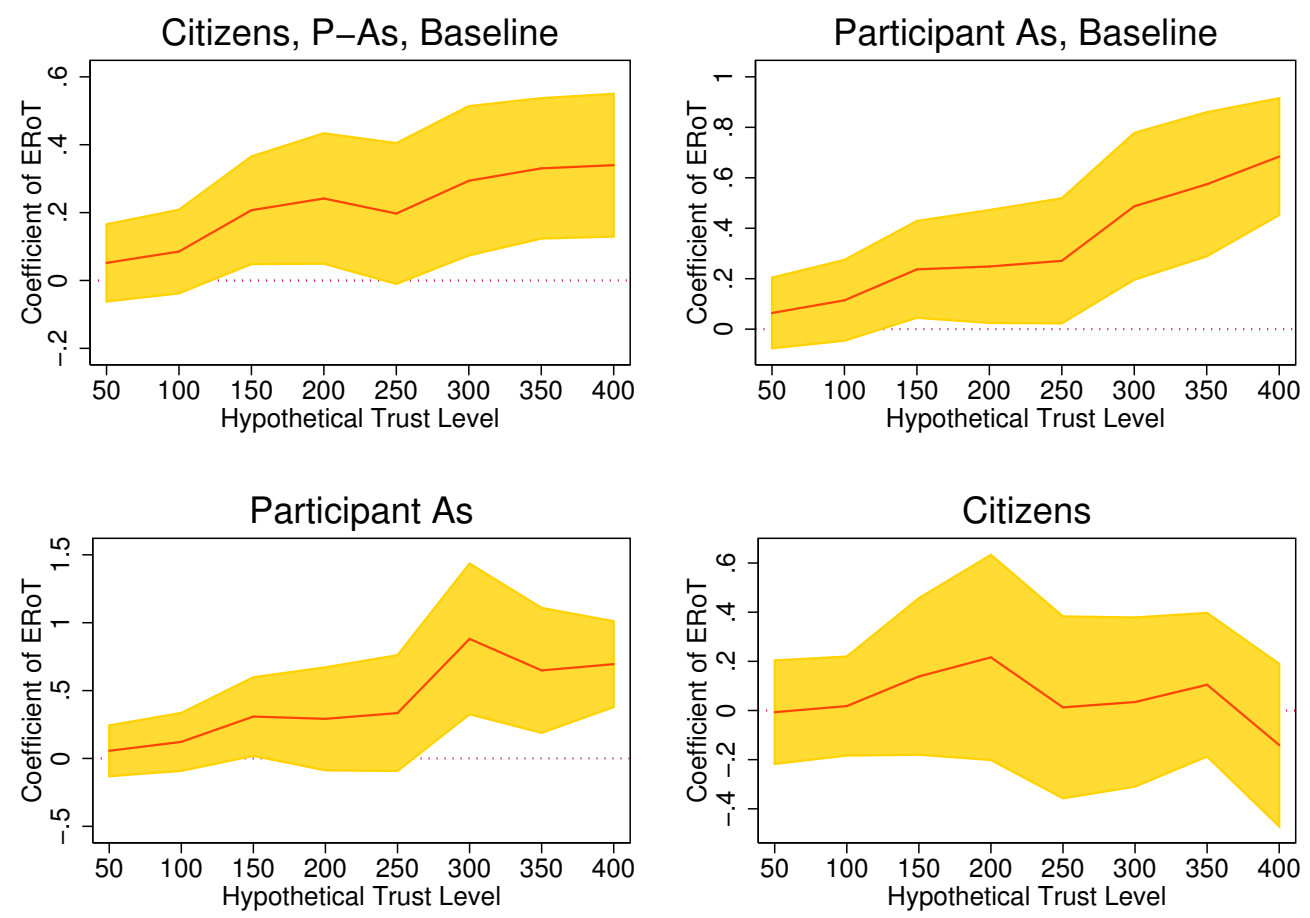

Each panel plots the regression coefficients for each subgroup. The coefficient is significantly different from zero when it comes to the baseline subjects and P-As. However, it is not different from zero for the Citizens i.e. WVS trust question does not predict Citizens' belief about how trustworthy others are. 
aims: one, to investigate if people interpreted the WVS trust question in the same way in India - a socio-cultural environment very different from the West, where the literature is currently located; two, to understand under what conditions, if any, the correspondence between WVS trust and behavior in lab based Trust Games held and under what condition it did not. So far as the second objective is concerned, our hypothesis was the following. If at all, the WVS trust question would be much better at capturing stable expectations about generalized behavior in a population than capturing short term variations in beliefs. We tested this hypothesis using a experimental design where subjects where induced a negative shock to their beliefs about how others would behave by making them go through a negative experience. In our case the negative experience was driven by extraction of a bribe from a subject's entitlement - an earned prize, in a simulated corruption game. The comparison group comprised of subjects who either did not go through the bribery game experience or went through an experience in a strategically identical but differently framed ultimatum game.

At one level our findings corroborate findings from Sapienza et al. (2013) as we find that WVS trust does capture expectations about others' trustworthiness. However, there is an important difference. WVS trust question does well in capturing long term, globally determined, stable expectations about others' behavior - such expectations are determined over the long run through cumulative life experiences (e.g. Malmendier and Nagel (2011) show how long run risk attitudes are shaped by personal experiences in times of macroeconomic instability). However, it is ill-suited to capture the locally affected fluctuations in beliefs about how others will behave. That is precisely the reason why we found a correspondence between subjects' native expectations about others' behavior and response to the WVS trust question but not for the set of subjects who went through the bribe demand induced negative belief shock. This negative belief shock was most likely temporary in nature and perhaps would have had little bearing on decisions outside the immediate context. This is only an hypothesis - our experiment is not designed to identify whether or how these short term changes dissipate and the long run steady state beliefs are arrived at. Despite that, it is important to conceptually distinguish between the two and the fact that survey based elicitations are only well poised to identify stable expectations and not short term changes in beliefs.

An interesting aspect of our finding is people do not seem to generalize local experiences to the population at large. In our setting of course subjects were familiar with the population. It will be interesting to see whether subjects generalize local behavior to a wider pan societal contexts immediately in a setting where they are not familiar with the population. The process of generalization has important implications for how stereotypes are formed. This is an angle which needs further investigation.

The implication of our finding is the following. After the important work of Dohmen et al. (2011), who find a robust correspondence between elicited risk in experiments and a survey question on attitude to risk in general, a number of studies, including ours, have come to rely on the survey based question about generalized risk to measure risk preference. The convenience of replacing a 
treatment by a question is hard to overstate. If other survey based questions were to be found to robustly measure other behavioral correlates, then we could, at least in principle, replace costly experiments with such survey based measures. Our study shows that in the context of measuring beliefs about others' trustworthiness, we cannot make a blanket use of the WVS trust question since it cannot capture the short term changes in locally formed beliefs. The reference group, which dictates behavior in Trust Games, especially in a homogenous subject pool like in our case, is typically different from the reference group people have in mind when they answer the WVS trust question. As a result, Trust Games and the WVS trust question remain relevant in their respective domains of inquiry, namely, behavioral analysis in the short run and generalized expectations about trustworthiness in the long run, respectively.

Throughout this paper, as perhaps elsewhere in the literature, we used the words "expectation" and "belief" interchangeably. Perhaps we should develop a consistent typological distinction between the different notions of beliefs - global expectations and local beliefs. Global expectations may be thought of as a steady state belief, it is stable and is formed through our aggregate experiences or a series of local experiences. Conceptually, this is the relevant notion of belief we have when we talk about rational expectations. On the other hand, local beliefs are short term perturbations caused by psychological triggers from immediate experiences. These perturbations are inherently unstable and likely to converge to the global expectations soon after.

\section{References}

Abbink, Klaus, Utteeyo Dasgupta, Lata Gangadharan, and Tarun Jain, "Letting the briber go free: An experiment on mitigating harassment bribes," Journal of Public Economics, $2014,111(\mathrm{C}), 17-28$.

Alatas, Vivi, Lisa Cameron, Ananish Chaudhuri, Nisvan Erkal, and Lata Gangadharan, "Subject pool effects in a corruption experiment: A comparison of Indonesian public servants and Indonesian students," Experimental Economics, March 2009, 12 (1), 113-132.

Banerjee, Ritwik, "Corruption, Norm Violation and Decay in Social Capital," Economics Working Papers 2015-05, School of Economics and Management, University of Aarhus November 2015.

_ , "On the interpretation of bribery in a laboratory corruption game: moral frames and social norms," Experimental Economics, 2016, 19 (1), 240-267.

Bellemare, Charles and Sabine Kroger, "On representative social capital," European Economic Review, January 2007, 51 (1), 183-202.

Berg, Joyce, John Dickhaut, and Kevin McCabe, "Trust, Reciprocity, and Social History," Games and Economic Behavior, July 1995, 10 (1), 122-142. 
Burnham, Terence, Kevin McCabe, and Vernon L. Smith, "Friend-or-foe intentionality priming in an extensive form trust game," Journal of Economic Behavior \& Organization, September 2000, 43 (1), 57-73.

Buser, Thomas and Anna Dreber, "The Flipside of Comparative Payment Schemes," Tinburgen Institute Discussion Paper TI 2013-190/1, Tinburgen Institute 2013.

Cameron, Lisa, Ananish Chaudhuri, Nisvan Erkal, and Lata Gangadharan, "Propensities to engage in and punish corrupt behavior: Experimental evidence from Australia, India, Indonesia and Singapore," Journal of Public Economics, August 2009, 93 (7-8), 843-851.

Dohmen, Thomas, Armin Falk, David Huffman, Uwe Sunde, Jurgen Schupp, and Gert G. Wagner, "Individual Risk Attitudes: Measurement, Determinants, And Behavioral Consequences," Journal of the European Economic Association, 06 2011, 9 (3), 522-550.

Drouvelis, Michalis, Robert Metcalfe, and Nattavudh Powdthavee, "Priming Cooperation in Social Dilemma Games," IZA Discussion Papers 4963, Institute for the Study of Labor (IZA) May 2010.

Fehr, Ernst, Urs Fischbacher, Jurgen Schupp, Bernhard von Rosenbladt, and Gert Georg Wagner, "A Nationwide Laboratory Examining Trust and Trustworthiness by Integrating Behavioural Experiments into Representative Surveys," CEPR Discussion Papers 3858, C.E.P.R. Discussion Papers April 2003.

Glaeser, Edward L., David I. Laibson, Jose A. Scheinkman, and Christine L. Soutter, "Measuring Trust," The Quarterly Journal of Economics, 2000, 115 (3), 811-846.

Guiso, Luigi, Paola Sapienza, and Luigi Zingales, "The Role of Social Capital in Financial Development," American Economic Review, June 2004, 94 (3), 526-556.

_ , _ , and _ , "Trusting the Stock Market," Journal of Finance, December 2008, 63 (6), 2557-2600.

_ , _, and _ , "Cultural Biases in Economic Exchange?," The Quarterly Journal of Economics, August 2009, 124 (3), 1095-1131.

Knack, Stephen and Philip Keefer, "Does Social Capital Have an Economic Payoff? A Cross-Country Investigation," The Quarterly Journal of Economics, 1997, 112 (4), 1251-1288.

Lazzarini, S. G., R. C Madalozzo, R. Artes, and J. O. Siqueira, "Measuring trust: An experiment in Brazil," Insper Working Papers 42, Insper Working Paper, Insper Instituto de Ensino e Pesquisa October 2004.

Maggian, Valeria and MarieClaire Villeval, "Social preferences and lying aversion in children," Experimental Economics, 2015, pp. 1-23. 
Malmendier, Ulrike and Stefan Nagel, "Depression Babies: Do Macroeconomic Experiences Affect Risk Taking?*," The Quarterly Journal of Economics, 2011, 126 (1), 373-416.

Rosaz, Julie and Marie Claire Villeval, "Lies and biased evaluation: A real-effort experiment," Journal of Economic Behavior \&5 Organization, 2012, 84 (2), 537 - 549.

Sapienza, Paola, Anna Toldra-Simats, and Luigi Zingales, "Understanding Trust," The Economic Journal, 2013, 123 (573), 1313-1332.

Thöni, Christian, Jean-Robert Tyran, and Erik Wengström, "Microfounrations of Social Capital," Journal of Public Economics, 2012, 96 (78), 635-643. 
Table 2: Marginal Effects from Probit Regression of WVS trust on trust, trustworthiness and ERoT

\begin{tabular}{|c|c|c|c|c|c|c|c|c|}
\hline & (1) & $(2)$ & (3) & (4) & $(5)$ & (6) & $(7)$ & (8) \\
\hline VARIABLES & if sent 50 & if sent 100 & if sent 150 & if sent 200 & if sent 250 & if sent 300 & if sent 350 & if sent 400 \\
\hline \multicolumn{9}{|l|}{ Panel 2(A) } \\
\hline trustworthiness & $\begin{array}{l}-0.08 \\
(0.12)\end{array}$ & $\begin{array}{l}-0.00 \\
(0.14)\end{array}$ & $\begin{array}{c}0.07 \\
(0.18)\end{array}$ & $\begin{array}{c}0.13 \\
(0.20)\end{array}$ & $\begin{array}{c}0.26 \\
(0.23)\end{array}$ & $\begin{array}{l}0.43^{*} \\
(0.24)\end{array}$ & $\begin{array}{l}0.45^{*} \\
(0.25)\end{array}$ & $\begin{array}{l}0.48^{*} \\
(0.25)\end{array}$ \\
\hline $\begin{array}{l}\text { Observations } \\
\text { Pseudo R-sq }\end{array}$ & $\begin{array}{c}218 \\
0.00187\end{array}$ & $\begin{array}{c}218 \\
2.10 \mathrm{e}-06\end{array}$ & $\begin{array}{c}218 \\
0.000518\end{array}$ & $\begin{array}{c}218 \\
0.00155\end{array}$ & $\begin{array}{c}218 \\
0.00477\end{array}$ & $\begin{array}{c}218 \\
0.0112\end{array}$ & $\begin{array}{c}218 \\
0.0121\end{array}$ & $\begin{array}{c}218 \\
0.0132\end{array}$ \\
\hline \multicolumn{9}{|l|}{ Panel 2(B) } \\
\hline trustworthiness & $\begin{array}{c}-0.11 \\
(0.12) \\
0.06 \\
(0.05)\end{array}$ & $\begin{array}{l}-0.10 \\
(0.15) \\
0.10^{*} \\
(0.05)\end{array}$ & $\begin{array}{c}-0.16 \\
(0.19) \\
0.21^{* * *} \\
(0.07)\end{array}$ & $\begin{array}{c}-0.17 \\
(0.23) \\
0.26^{* * *} \\
(0.08)\end{array}$ & $\begin{array}{c}-0.03 \\
(0.25) \\
0.24^{* * *} \\
(0.09)\end{array}$ & $\begin{array}{c}0.06 \\
(0.27) \\
0.28 * * * \\
(0.10)\end{array}$ & $\begin{array}{c}0.05 \\
(0.28) \\
0.28^{* * *} \\
(0.09)\end{array}$ & $\begin{array}{c}0.04 \\
(0.29) \\
0.27^{* * *} \\
(0.09)\end{array}$ \\
\hline $\begin{array}{l}\text { Observations } \\
\text { Pseudo R-sq }\end{array}$ & $\begin{array}{c}218 \\
0.00746\end{array}$ & $\begin{array}{c}218 \\
0.0110\end{array}$ & $\begin{array}{c}218 \\
0.0309\end{array}$ & $\begin{array}{c}218 \\
0.0353\end{array}$ & $\begin{array}{c}218 \\
0.0325\end{array}$ & $\begin{array}{c}218 \\
0.0406\end{array}$ & $\begin{array}{c}218 \\
0.0445\end{array}$ & $\begin{array}{c}218 \\
0.0433\end{array}$ \\
\hline \multicolumn{9}{|l|}{ Panel 2( C) } \\
\hline $\begin{array}{l}\text { ERoT } \\
\text { risk }\end{array}$ & $\begin{array}{c}0.04 \\
(0.04) \\
0.08^{* * *} \\
(0.01)\end{array}$ & $\begin{array}{c}0.08 \\
(0.05) \\
0.08^{* * *} \\
(0.01)\end{array}$ & $\begin{array}{c}0.17^{* * *} \\
(0.06) \\
0.07 * * * \\
(0.01)\end{array}$ & $\begin{array}{c}0.20 * * * \\
(0.07) \\
0.07 * * * \\
(0.01)\end{array}$ & $\begin{array}{c}0.22^{* * *} \\
(0.07) \\
0.07^{* * *} \\
(0.01)\end{array}$ & $\begin{array}{c}0.26 * * * \\
(0.08) \\
0.07^{* * *} \\
(0.01)\end{array}$ & $\begin{array}{c}0.26 * * * \\
(0.08) \\
0.07^{* * *} \\
(0.01)\end{array}$ & $\begin{array}{c}0.24^{* * *} \\
(0.07) \\
0.07^{* * *} \\
(0.01)\end{array}$ \\
\hline $\begin{array}{c}\text { Observations } \\
\text { Pseudo R-sq }\end{array}$ & $\begin{array}{c}218 \\
0.0938\end{array}$ & $\begin{array}{c}218 \\
0.0996\end{array}$ & $\begin{array}{c}218 \\
0.117\end{array}$ & $\begin{array}{c}218 \\
0.119\end{array}$ & $\begin{array}{c}218 \\
0.120\end{array}$ & $\begin{array}{c}218 \\
0.128\end{array}$ & $\begin{array}{c}218 \\
0.130\end{array}$ & $\begin{array}{c}218 \\
0.126\end{array}$ \\
\hline
\end{tabular}

\footnotetext{
$\dagger$ Note: Numbers in the parentheses represent the Standard errors. ${ }^{* * *} \mathrm{p}<0.01,{ }^{* *} \mathrm{p}<0.05,{ }^{*} \mathrm{p}<0.1$. The dependent variable is WVS-trust. The dependent variable in col (1) is trust while that in col (2) - (9) is trustworthiness measured in terms of Return Ratio for each possible amount sent by the sender.
} 
Table 3: Marginal Effects from Probit Regression of WVS trust on ERoT and Risk

\begin{tabular}{|c|c|c|c|c|c|c|c|c|}
\hline & (1) & $(2)$ & (3) & (4) & (5) & $(6)$ & (7) & (8) \\
\hline Panel (A) & if sent 50 & if sent 100 & if sent 150 & if sent 200 & if sent 250 & if sent 300 & if sent 350 & if sent 400 \\
\hline \multirow[t]{2}{*}{ ERoT } & 0.05 & 0.09 & $0.21^{* *}$ & $0.24^{* *}$ & $0.20^{*}$ & $0.29^{* * *}$ & $0.33^{* * *}$ & $0.34^{* * *}$ \\
\hline & $(0.06)$ & $(0.06)$ & $(0.08)$ & $(0.10)$ & $(0.11)$ & $(0.11)$ & $(0.11)$ & $(0.11)$ \\
\hline \multirow[t]{2}{*}{ risk } & $0.08^{* * *}$ & $0.08^{* * *}$ & $0.08^{* * *}$ & $0.07^{* * *}$ & $0.08^{* * *}$ & $0.07^{* * *}$ & $0.08^{* * *}$ & $0.07^{* * *}$ \\
\hline & $(0.02)$ & $(0.02)$ & $(0.02)$ & $(0.02)$ & $(0.02)$ & $(0.02)$ & $(0.02)$ & $(0.02)$ \\
\hline Observations & 127 & 127 & 127 & 127 & 127 & 127 & 127 & 127 \\
\hline Pseudo R-sq & 0.0868 & 0.0930 & 0.119 & 0.117 & 0.102 & 0.122 & 0.137 & 0.137 \\
\hline \multicolumn{9}{|l|}{ Panel (B) } \\
\hline \multirow[t]{2}{*}{ ERoT } & 0.06 & 0.11 & $0.24^{* *}$ & $0.25^{* *}$ & $0.27 * *$ & $0.49^{* * *}$ & $0.57^{* * *}$ & $0.68^{* * *}$ \\
\hline & $(0.07)$ & $(0.08)$ & $(0.10)$ & $(0.11)$ & $(0.13)$ & $(0.15)$ & $(0.15)$ & $(0.12)$ \\
\hline \multirow[t]{2}{*}{ risk } & $0.08^{* * *}$ & $0.07^{* * *}$ & $0.07^{* * *}$ & $0.07^{* * *}$ & $0.07^{* * *}$ & $0.07^{* * *}$ & $0.07^{* * *}$ & $0.07^{* * *}$ \\
\hline & $(0.02)$ & $(0.02)$ & $(0.02)$ & $(0.02)$ & $(0.02)$ & $(0.02)$ & $(0.02)$ & $(0.02)$ \\
\hline Observations & 81 & 81 & 81 & 81 & 81 & 81 & 81 & 81 \\
\hline Pseudo R-sq & 0.094 & 0.104 & 0.134 & 0.128 & 0.125 & 0.165 & 0.184 & 0.242 \\
\hline \multicolumn{9}{|l|}{ Panel (C ) } \\
\hline \multirow[t]{2}{*}{ ERoT } & 0.06 & 0.12 & $0.31^{* *}$ & 0.29 & 0.33 & $0.88^{* * *}$ & $0.65^{* * *}$ & $0.69^{* * *}$ \\
\hline & $(0.10)$ & $(0.11)$ & $(0.15)$ & $(0.19)$ & $(0.22)$ & $(0.28)$ & $(0.23)$ & $(0.16)$ \\
\hline \multirow[t]{2}{*}{ risk } & $0.08^{* *}$ & $0.08^{* *}$ & $0.08^{* * *}$ & $0.07^{* *}$ & $0.06^{* *}$ & $0.05^{* *}$ & $0.06^{* *}$ & $0.06^{* *}$ \\
\hline & $(0.03)$ & $(0.03)$ & $(0.03)$ & $(0.03)$ & $(0.03)$ & $(0.03)$ & $(0.03)$ & $(0.03)$ \\
\hline Observations & 45 & 45 & 45 & 45 & 45 & 45 & 45 & 45 \\
\hline Pseudo R-sq & 0.0713 & 0.0848 & 0.125 & 0.102 & 0.105 & 0.216 & 0.187 & 0.265 \\
\hline \multicolumn{9}{|l|}{ Panel (D) } \\
\hline \multirow[t]{2}{*}{ ERoT } & -0.01 & 0.02 & 0.14 & 0.22 & 0.01 & 0.03 & 0.10 & -0.14 \\
\hline & $(0.11)$ & $(0.10)$ & $(0.16)$ & $(0.21)$ & $(0.19)$ & $(0.17)$ & $(0.15)$ & $(0.17)$ \\
\hline \multirow[t]{2}{*}{ risk } & $0.09 * * *$ & $0.09 * * *$ & $0.09^{* * *}$ & $0.09^{* * *}$ & $0.09 * * *$ & $0.09^{* * *}$ & $0.09^{* * *}$ & $0.09^{* * *}$ \\
\hline & $(0.03)$ & $(0.03)$ & $(0.03)$ & $(0.03)$ & $(0.03)$ & $(0.03)$ & $(0.03)$ & $(0.03)$ \\
\hline Observations & 46 & 46 & 46 & 46 & 46 & 46 & 46 & 46 \\
\hline Pseudo R-sq & 0.110 & 0.111 & 0.123 & 0.128 & 0.110 & 0.111 & 0.119 & 0.122 \\
\hline
\end{tabular}

$\dagger$ Note: Numbers in the parentheses represent the Standard errors. ${ }^{* * *} \mathrm{p}<0.01,{ }^{* *} \mathrm{p}<0.05,{ }^{*} \mathrm{p}<0.1$. The dependent variable is WVS-trust. The independent variables are Expected Return on Trust (ERoT) and risk preference. Panel A includes Citizens(C), Participant As(P-A) and baseline subjects (BS), Panel B includes P-A and BS, Panel C includes P-A only and Panel D includes $\mathrm{C}$ only. The number of observations differs in the panels due to inclusion of different set of subjects in each panel.

\section{Appendix 1}


Table A1: Summary Statistics

\begin{tabular}{|c|c|c|c|c|c|}
\hline BG/UG Variables & Description & \multicolumn{2}{|c|}{ Mean } & \multicolumn{2}{|c|}{ Std. Dev } \\
\hline $\mathrm{BG}$ & $=1$ if Treatment is BG & \multirow{3}{*}{\multicolumn{2}{|c|}{$\begin{array}{c}0.51 \\
232.97 \\
91\end{array}$}} & \multirow{3}{*}{\multicolumn{2}{|c|}{$\begin{array}{c}0.50 \\
109.60\end{array}$}} \\
\hline amount & bribe/ultim demanded from $\mathrm{C} / \mathrm{P}-\mathrm{A}$ & & & & \\
\hline Observations & & & & & \\
\hline \multirow{2}{*}{ Trust and Demographic Variables } & & \multicolumn{2}{|c|}{ Full Sample } & \multicolumn{2}{|c|}{$\mathrm{C}+\mathrm{P}-\mathrm{A}+$ Baseline } \\
\hline & & Mean & Std. Dev. & Mean & Std. Dev. \\
\hline trust & Amount sent as a sender in Trust Game & 245.41 & 122.29 & 232.97 & 127.20 \\
\hline trustworthiness & $\begin{array}{c}\text { Return Ratio, averaged over all trust } \\
\text { categories. }\end{array}$ & 0.39 & 0.14 & 0.39 & 0.14 \\
\hline ERoT & Expected Return on Trust & -0.02 & 0.41 & -0.02 & 0.35 \\
\hline female & $=1$ if subject is Female & 0.26 & 0.44 & 0.25 & 0.44 \\
\hline age & Age & 24.37 & 1.81 & 24.35 & 1.86 \\
\hline score & CAT/GMAT score in percentile & 100.32 & 55.98 & 95.06 & 3.51 \\
\hline family_income & Family Income ${ }^{a}$ & 3.56 & 0.78 & 3.57 & 0.79 \\
\hline altruism & $\begin{array}{l}\text { Suppose you win a lottery of Rs. } 1000 . \text { How } \\
\text { much of it will you be willing to share with a } \\
\text { charity of your choice? }\end{array}$ & 294.27 & 142.32 & 283.52 & 141.43 \\
\hline risk & $\begin{array}{c}\text { How do you see yourself: are you generally a } \\
\text { person who is fully prepared to take risks or } \\
\text { do you try to avoid taking risks? }\end{array}$ & 5.76 & 2.00 & 5.90 & 1.86 \\
\hline \multirow{3}{*}{\multicolumn{2}{|c|}{$\begin{array}{c}\text { Cronbach's alpha for Return Ratio }{ }^{b} \\
\text { Cronbach's alpha for } \operatorname{ERoT}^{b} \\
\text { Observations }\end{array}$}} & \multirow{3}{*}{\multicolumn{2}{|c|}{$\begin{array}{l}0.86 \\
0.92 \\
218\end{array}$}} & \multirow{3}{*}{\multicolumn{2}{|c|}{$\begin{array}{c}0.86 \\
0.90 \\
91\end{array}$}} \\
\hline & & & & & \\
\hline & & & & & \\
\hline \multicolumn{6}{|c|}{ Demographic Balance across Treatments } \\
\hline \multicolumn{2}{|r|}{ Variables } & $\mathrm{BG}$ & $\mathrm{UG}$ & \multicolumn{2}{|l|}{ Baseline } \\
\hline & 0.28 & 0.25 & \multicolumn{2}{|l|}{0.25} \\
\hline \multicolumn{2}{|r|}{ age } & 24 & 24.5 & \multicolumn{2}{|l|}{24.4} \\
\hline \multicolumn{2}{|c|}{ score } & 101.2 & 95.1 & \multicolumn{2}{|l|}{111.4} \\
\hline \multicolumn{2}{|c|}{ family_income } & 3.7 & 3.4 & \multicolumn{2}{|l|}{3.7} \\
\hline
\end{tabular}

${ }^{a}$ Categorical variable where category 1: <Rs. 20,000, 2: between Rs. 20,001 and Rs. 50,000, 3: between Rs. 50,001 and Rs. 1,00,000 and 4: >Rs. 1,00,001.

${ }^{b}$ A measure of internal consistency, i.e. how closely related the set of items are as a group. 
Table A2: Alternative measures of trust and the mutual correlations

(a) Definitions of different measures of trust used in the survey

\begin{tabular}{|c|c|c|c|}
\hline Variable & Description/Question & Values & Percentage/Mean \\
\hline \multirow[b]{2}{*}{ trust_wvs } & \multirow{2}{*}{$\begin{array}{l}\text { Generally speaking, would you say that } \\
\text { most people can be trusted or that you } \\
\text { need to be very careful in dealing with } \\
\text { people? }\end{array}$} & Most people can be trusted & $68 \%$ \\
\hline & & Need to be very careful & $32 \%$ \\
\hline \multirow[t]{2}{*}{ advantage } & \multirow{2}{*}{$\begin{array}{l}\text { Do you think most people would try to } \\
\text { take advantage of you if they got the } \\
\text { chance, or would they try to be fair? }\end{array}$} & $\begin{array}{l}\text { Most of the time they } \\
\text { would try to be fair }\end{array}$ & $63 \%$ \\
\hline & & $\begin{array}{l}\text { Most of the time they } \\
\text { would try to take advantage }\end{array}$ & $37 \%$ \\
\hline wallet & $\begin{array}{l}\text { Suppose you left your wallet in the } \\
\text { Metro. On a scale of } 1 \text { to } 10 \text {, how } \\
\text { much do you think are the chances } \\
\text { that you will get it back? }\end{array}$ & $\begin{array}{l}1 \text { (almost no chance) to } \\
10 \text { (very high chance) }\end{array}$ & 3.04 \\
\hline
\end{tabular}

(b) Raw Correlations among Survey Trust Questions. The numbers in the brackets represent $p$-values.

\begin{tabular}{cccc}
\hline & trust_wvs & advantage & wallet \\
\hline \hline trust_wvs & 1 & & \\
advantage & - & & \\
& $(0.21$ & 1 & \\
wallet & 0.10 & 0.10 & 1 \\
& $(0.13)$ & $(0.14)$ & \\
\hline
\end{tabular}


Table 3: (a) Variation of Expected Return on Trust on different treatments

\begin{tabular}{|c|c|c|c|c|c|c|c|c|}
\hline & (1) & $(2)$ & (3) & (4) & (5) & (6) & (7) & (8) \\
\hline Variables & if sent 50 & if sent 100 & if sent 150 & if sent 200 & if sent 250 & if sent 300 & if sent 350 & if sent 400 \\
\hline \multirow[t]{2}{*}{ UG } & $0.30 * *$ & $0.34^{* * *}$ & $0.21^{* *}$ & 0.11 & 0.05 & 0.09 & 0.02 & 0.03 \\
\hline & $(0.14)$ & $(0.13)$ & $(0.09)$ & $(0.08)$ & $(0.08)$ & $(0.08)$ & $(0.08)$ & $(0.08)$ \\
\hline \multirow[t]{2}{*}{ Base } & $0.32^{* *}$ & $0.44^{* * *}$ & $0.40 * * *$ & $0.27^{* * *}$ & $0.17^{* *}$ & 0.13 & 0.02 & -0.02 \\
\hline & $(0.14)$ & $(0.13)$ & $(0.10)$ & $(0.08)$ & $(0.08)$ & $(0.08)$ & $(0.08)$ & $(0.08)$ \\
\hline \multirow[t]{2}{*}{ female } & -0.21 & -0.03 & 0.03 & 0.05 & 0.09 & 0.06 & 0.04 & -0.03 \\
\hline & $(0.14)$ & $(0.13)$ & $(0.09)$ & $(0.08)$ & $(0.08)$ & $(0.08)$ & $(0.08)$ & $(0.08)$ \\
\hline \multirow[t]{2}{*}{ age } & 0.01 & 0.02 & 0.02 & $0.03^{*}$ & 0.02 & 0.02 & 0.01 & -0.01 \\
\hline & $(0.03)$ & $(0.03)$ & $(0.02)$ & $(0.02)$ & $(0.02)$ & $(0.02)$ & $(0.02)$ & $(0.02)$ \\
\hline \multirow[t]{2}{*}{ income } & -0.03 & -0.01 & -0.02 & -0.00 & -0.01 & -0.03 & -0.02 & -0.03 \\
\hline & $(0.08)$ & $(0.07)$ & $(0.05)$ & $(0.05)$ & $(0.05)$ & $(0.04)$ & $(0.05)$ & $(0.05)$ \\
\hline \multirow[t]{2}{*}{ score } & -0.00 & -0.00 & $-0.00^{* *}$ & $-0.00 * * *$ & $-0.00^{*}$ & -0.00 & -0.00 & -0.00 \\
\hline & $(0.00)$ & $(0.00)$ & $(0.00)$ & $(0.00)$ & $(0.00)$ & $(0.00)$ & $(0.00)$ & $(0.00)$ \\
\hline \multirow[t]{2}{*}{ Constant } & -0.51 & -0.81 & -0.55 & -0.68 & -0.42 & -0.05 & 0.14 & 0.65 \\
\hline & $(0.95)$ & $(0.87)$ & $(0.64)$ & $(0.56)$ & $(0.54)$ & $(0.53)$ & $(0.56)$ & $(0.54)$ \\
\hline Obs & 127 & 127 & 127 & 127 & 127 & 127 & 127 & 127 \\
\hline R-squared & 0.089 & 0.116 & 0.162 & 0.148 & 0.080 & 0.056 & 0.014 & 0.016 \\
\hline
\end{tabular}

$\dagger$ Note: Numbers in the parentheses represent the Standard errors. ${ }^{* * *} \mathrm{p}<0.01,{ }^{* *} \mathrm{p}<0.05,{ }^{*} \mathrm{p}<0.1$. The independent variables are Expected Return on Trust (ERoT) for each hypothetical amount sent. The difference in ERoT across treatments is obtained from the two treatment dummies: UG - dummy variable for the UG treatment and Base - dummy variable for the baseline treatment. 
Table A3: (b) Variation of Expected Return on Trust on different treatments from pooled data

\begin{tabular}{rcc}
\hline & $(1)$ & $(2)$ \\
Variables & ERoT & ERoT \\
UG & $0.15^{* * *}$ & $0.14^{* * *}$ \\
& $(0.04)$ & $(0.04)$ \\
Base & $0.19^{* * *}$ & $0.21^{* * *}$ \\
& $(0.04)$ & $(0.04)$ \\
female & & -0.00 \\
& & $(0.04)$ \\
age & & $0.02^{*}$ \\
& & $(0.01)$ \\
income & & -0.02 \\
& & $(0.02)$ \\
score & & $-0.00 * * *$ \\
& & $(0.00)$ \\
Constant & $-0.08^{* * *}$ & -0.28 \\
& $(0.03)$ & $(0.26)$ \\
& & 1,016 \\
R-squared & 0.028 & 0.050 \\
\hline
\end{tabular}

${ }^{\dagger}$ Note: Numbers in the parentheses represent the Standard errors. ${ }^{* * *} \mathrm{p}<0.01,{ }^{* *} \mathrm{p}<0.05,{ }^{*} \mathrm{p}<0.1$. The independent variable is Expected Return on Trust (ERoT) pooled together for all possible amount sent. The difference in pooled ERoT across treatments is obtained from the two treatment dummies: UG - dummy variable for the UG treatment and Base - dummy variable for the baseline treatment. 
Table A4: Marginal Effects from Probit Regression of WVS trust on ERoT with treatment interaction terms

\begin{tabular}{|c|c|c|c|c|c|c|c|c|}
\hline & (1) & $(2)$ & (3) & (4) & (5) & (6) & (7) & (8) \\
\hline & if sent 50 & sent 100 & f sent 150 & if sent 200 & if sent 250 & if sent 300 & if sent 350 & if sent 400 \\
\hline BG & $\begin{array}{l}-0.06 \\
(0.09)\end{array}$ & $\begin{array}{l}-0.05 \\
(0.09)\end{array}$ & $\begin{array}{l}-0.03 \\
(0.08)\end{array}$ & $\begin{array}{l}-0.03 \\
(0.08)\end{array}$ & $\begin{array}{c}-0.03 \\
(0.08)\end{array}$ & $\begin{array}{c}0.29^{*} \\
(0.17)\end{array}$ & $\begin{array}{c}0.15 \\
(0.15)\end{array}$ & $\begin{array}{c}0.27^{* *} \\
(0.13)\end{array}$ \\
\hline ERoT & $\begin{array}{c}0.02 \\
(0.08)\end{array}$ & $\begin{array}{c}0.10 \\
(0.10)\end{array}$ & $\begin{array}{c}0.28^{* *} \\
(0.14)\end{array}$ & $\begin{array}{l}0.31^{*} \\
(0.17)\end{array}$ & $\begin{array}{l}0.37^{* *} \\
(0.18)\end{array}$ & $\begin{array}{c}1.08^{* * *} \\
(0.40)\end{array}$ & $\begin{array}{c}0.72^{* * *} \\
(0.28)\end{array}$ & $\begin{array}{c}0.81^{* * *} \\
(0.23)\end{array}$ \\
\hline $\mathrm{BG} \times \mathrm{ERoT}$ & $\begin{array}{c}0.00 \\
(0.13)\end{array}$ & $\begin{array}{l}-0.04 \\
(0.14)\end{array}$ & $\begin{array}{l}-0.09 \\
(0.21)\end{array}$ & $\begin{array}{l}-0.04 \\
(0.27)\end{array}$ & $\begin{array}{l}-0.36 \\
(0.26)\end{array}$ & $\begin{array}{c}-1.04^{* *} \\
(0.43)\end{array}$ & $\begin{array}{c}-0.64^{* *} \\
(0.32)\end{array}$ & $\begin{array}{c}-0.88^{* * *} \\
(0.27)\end{array}$ \\
\hline Observations & 91 & 91 & 91 & 91 & 91 & 91 & 91 & 91 \\
\hline Pseudo R-sq & 0.00520 & 0.0134 & 0.0385 & 0.0379 & 0.0310 & 0.0849 & 0.0745 & 0.102 \\
\hline
\end{tabular}

Standard errors in parentheses ** $\mathrm{p}<0.01,{ }^{* *} \mathrm{p}<0.05,{ }^{*} \mathrm{p}<0.1$

$\dagger$ Note: Numbers in the parentheses represent the Standard errors. ${ }^{* * *} \mathrm{p}<0.01,{ }^{* *} \mathrm{p}<0.05,{ }^{*} \mathrm{p}<0.1$. The dependent variable is WVS-trust. The independent variables are Expected Return on Trust (ERoT). 


\section{Appendix 2}

\section{Instructions for the Bribery and Ultimatum Game fol- lowed by Baseline Trust Game}

\section{Welcome.}

You are now taking part in an economic experiment. If you read the following instructions carefully, you can, depending on your decisions and the decisions of other participants, earn a considerable amount of money. It is prohibited to communicate with the other participants during the experiment. Should you have any questions please raise your hand and we will come to you. This is an anonymous experiment and you will not know either the identity or the choices that others know. We will give each one of you an identity number which will facilitate your payments.

\section{Overview}

The experiment consists of 2 parts and a survey. Please start by reading the instructions for the first part carefully. You will receive the instructions for the second part after the first part is finished. And so on.

\section{Earnings}

During the experiment you can earn money by receiving a fictitious currency called "mohar". All mohars that you earn in the experiment will be exchanged into Rupees at the end of the experiment, The exchange rate is: 1 mohar $=\operatorname{Rs} 0.50$ (M denotes mohar henceforth). We will pay you 200 mohars for participating but you can earn additional money depending on the decisions you and the others make. The experiment consists of two parts but remember you will be randomly paid for only one of the two parts which will be determined by a toss. Since you donot know which one you will be paid for, make your decisions for both the parts carefully.

\subsection{Part 1 : Subject given either 1.1 .1 or 1.1 .2}

\subsubsection{Bribery Game}

You may be paired with another participant in this experiment. The matching of two participants will be randomly done. You will not be informed of the identity of the participant with whom you have been matched.

Each participant today will receive a base participation fee of $200 \mathrm{M}$. We have divided the total number of participants in this experiment session randomly into two equal groups: Citizens (C) and Public Officials (PO).

A Citizen performs a task in ten minutes. Her task is to count the number of occurrences of the letter "A" from a random sequence of letters. She has to perform this task for five different sequences of letters. If she is unable to complete the task in ten minutes then she leaves the game with her participation fee of $200 \mathrm{M}$ and the Public Official gets $600 \mathrm{M}$. If she successfully does complete the task she is entitled to a payment of $400 \mathrm{M}$ (in addition to participation fee of 200 $\mathrm{M})$. However before the experimenter hands over the entitlement to the Citizen, she needs the approval of the Public Official who receives a salary of $400 \mathrm{M}$ for his job of approval (in addition to participation fee of $200 \mathrm{M}$ ). A Public Official, however, can ask for a bribe before approving the entitlement for the corresponding Citizen. He may ask for a bribe of 100, 200, 300, 400 M. He may choose not to ask for a bribe as well i.e. ask for 0 bribe. The information for demand for bribe then is forwarded to the Citizen who can then decide whether to Accept or Reject the demand for 
bribe. The final earnings will depend on the final choices each one makes i.e. PO's choices about demand for bribe, C's choices about Acceptance or Rejection. Suppose PO demands a bribe $b$. If C accepts the demand then $\mathrm{PO}$ gets $(600+b) \mathrm{M}$ and $\mathrm{C}$ gets $(200+b) \mathrm{M}$. If she rejects the earnings then $\mathrm{C}$ and PO get only $600 \mathrm{M}$ and $200 \mathrm{M}$, respectively.

Take a look at the figure below to further clarify the rules of the game and the earnings.

Please go through the two examples given below.

Example. Citizen completes the task. She is entitled to a payment of $600 \mathrm{M}$. Public Official demands a bribe of $100 \mathrm{M}$ for himself. Citizen accepts it. Public Official's earning is $200+400+100=700$ M. Citizen's earning is $200+400-100=500 \mathrm{M}$.

Example. Citizen completes the task. She is entitled to a payment of $600 \mathrm{M}$. Public Official demands for a bribe of $400 \mathrm{M}$ for himself. Citizen rejects it. Public Official's earning is $600+0=600$ M. Citizen's earning is $200+0=200 \mathrm{M}$.

\section{Instruction for Citizens}

In this room all of you are Citizens. Note that you are matched anonymously with a participant sitting in the other room. He is your corresponding Public Official who is in charge of approving your entitlement if you do earn it.

In order to earn the entitlement of $400 \mathrm{M}$, you have to perform a simple task in 10 minutes following which you will earn the key to your entitlement. What you will see is five sequences of some random letters. Your task is to count the exact number of 'A's for each of the sequences. Only when you have correctly counted the number of As for a sequence will you be able to go to the next sequence. When you count successfully for all the sequence you will receive the key for your entitlement and you can use the key to make your choices subsequently.

In order to complete the task, click here to count the number of As for the five sequences of random letters.

1. Input your Identity number. Enter the correct the number of 'A's for each of the five sequences.

2. If you have completed counting the number of As, please write down the Key to your entitlement on a piece of paper and proceed. If you have not been able to complete the task in ten minutes then you can collect your participation fee and leave.

Right click here and open the link in a new tab to input your choices

3. Please indicate on the response sheet and on the website whether you accept or reject the demand for bribe for all possible bribe amount. We will match your response with the actual bribe amount demanded and determine your earnings.

4. We will now collect your responses and match them with the response of your corresponding Public Official.

5. You will now receive the response sheet, which mentions the bribe demanded, your acceptance/rejection decision and the final earning from this part.

\section{Instruction for Public Officials}

In this room all of you are Public Officials. You are responsible for the approving the entitlement for the Citizens. Before approving you can ask for a bribe from the Citizen. You may also choose not to ask for a bribe.

1. Now make your decision whether to ask for a bribe before you approve the entitlement for the Citizen and if yes how much to ask for. Click here to input your choice.

2. We now collect your decision and match them with Citizen's acceptance/rejection decision. 


\subsubsection{Ultimatum Game}

\section{Common for Participant A and Participant B}

You may be paired with another participant in this experiment. The matching of two participants will be randomly done. You will not be informed of the identity of the participant with whom you have been matched.

Each participant today will receive a base participation fee of $200 \mathrm{M}$. We have divided the total number of participants in this experiment session randomly into two equal groups: Participant $\mathrm{A}$ (P-A) and Participant B (P-B).

Participant A performs a task in ten minutes. Her task is to count the number of occurrences of the letter "A" from a random sequence of letters. She has to perform this task for five different sequences of letters. If she cannot perform the task in ten minutes then she leaves the game with her participation fee $200 \mathrm{M}$ and P-B gets $600 \mathrm{M}$. If she successfully completes the task, then she is entitled to playing the next stage of the game i.e. she earns the right to play the second stage game. P-B's earning is 400M in addition to the participation fee of $200 \mathrm{M}$ (i.e. $600 \mathrm{M}$ ) for her role, which is the following. In the second stage $\mathrm{P}-\mathrm{B}$ decides to divide $400 \mathrm{M}$ between himself and P-A. For example if P-B keeps x with himself then P-A gets $400-\mathrm{x}$ M. The amount which P-B transfers can only be in multiple of 100s i.e. either 0, 100, 200, 300, 400 in which cases he gets 400, 300, 200, 100, 0, respectively, for himself. P-A can then decide whether or not to Accept or Reject the amount which is offered. If $\mathrm{P}-\mathrm{A}$ accepts the offer then $\mathrm{P}-\mathrm{B}$ gets $(600+\mathrm{x}) \mathrm{M}$ and $\mathrm{P}-\mathrm{A}$ gets $(200$ $+\mathrm{x}) \mathrm{M}$. If she rejects the earnings then P-A and P-B get only $600 \mathrm{M}$ and $200 \mathrm{M}$ respectively.

Take a look at the figure below to further clarify the rules of the game and the earnings.

Please go through the two examples given below.

Example. P-A completes the task and proceeds to the next round. P-B divides $400 \mathrm{M}$ into 100 $\mathrm{M}$ for himself and $300 \mathrm{M}$ for himself. P-A accepts it. P-B's earning is $200+400+100=700 \mathrm{M}$. P-A's earning is $200+400-100=500 \mathrm{M}$.

Example. P-A completes the task and proceeds to the next round. P-B divides $400 \mathrm{M}$ into $400 \mathrm{M}$ for himself and 0 for P-A. P-A rejects it. P-B's earning is $600+0=600 \mathrm{M}$. P-A's earning is $200+0=200 \mathrm{M}$.

\section{Instruction for Participant A}

In this room all of you are Participant As. Note that you are matched anonymously with a participant sitting in the other room, he is your corresponding Participant B whom you will play in second round.

In order to proceed to second round, you will have to perform a simple task in 10 minutes following which you will earn the key to the second round. What you will see is five sequences of some random letters. Your task is to count the exact number of 'A's for each of the sequences. Only when you have correctly counted the number of As for a sequence will you be able to go to the next sequence. When you count successfully for all the sequence you will receive the key and you can use the key to proceed.

1. Right click here and open the link in a new tab. Enter the correct the number of 'A's for each of the five sequences.

2. If you have completed counting the number of As, please write down the Key to your entitlement on a piece of paper and proceed. If you have not been able to complete the task in ten minutes then you can collect your participation fee and leave.

3. Please right click here and open a new tab and indicate on the response sheet whether you accept or reject the amount demanded for all possible transfer amount. We will match your response with the actual transfer amount and determine your earnings. 
4. We will now collect your responses and match them with the response of your corresponding P-B.

5. You will now receive the response sheet, which mentions the division proposed by P-B, your acceptance/rejection decision and the final earnings from this part.

\section{Instruction for Participant B}

In this room all of you are Participant B.

1. Now make your decision about how to divide $400 \mathrm{M}$ between yourself and Participant A i.e. whether to share anything with him, if yes how much. Please right click here to open a new link and input your decision. Your sharing amount should be in multiples of 100 .

2. We now collect your decision.

3. You are now being informed about whether your decision has been accepted and your and the P-A's earnings.

\subsection{Part 2: Trust Game: Common for Citizen and Public Official in BG and Participant A and Participant B in UG}

In this part a participation fee of $200 \mathrm{M}$ will be given to all participants.

You will now play the sending task. In this task, participants are divided into two groups: Senders and Receivers. Both the Senders and the Receivers are given 400 M. First Sender makes a decision. The Sender can choose to send 0, 100, 200, 300 or 400 M to the Receiver. Any amount sent will be tripled. The Sender keeps any amount of money not send to the Receiver.

The Receiver can send back any amount up to the total amount received (that is, the amount the Sender sent multiplied by 3).

Earnings The Sender's earnings in part 2 are $:=400 \mathrm{M}-$ any amount sent to the Receiver + any amount sent back to the Sender

The Receiver's earnings in part 2 are: = any amount received from the Sender multiplied by three - any amount sent back to the Sender.

You will be asked to make a decision both as a Sender and as a Receiver. One of your roles will be randomly picked. You will be matched with another randomly matched participant in the other role (note that your matched partner here will be different from the matched partner in Part 1). Your decision and the decision of the other player determine your earnings.

\section{Example}

You are in the role of a Sender. You have chosen to send $200 \mathrm{M}$ to the Receiver. Hence, the Receiver could send back between 0 and $600 \mathrm{M}(=3 \times 200 \mathrm{M})$. to you. The Receiver has chosen to send back $300 \mathrm{M}$ to you.

- Your earnings in Part 2 are therefore: $400 \mathrm{M}-200 \mathrm{M}$ (the amount you sent) + $300 \mathrm{M}$ (the amount received back) $=500 \mathrm{M}$.

- The earnings of the Receiver in Part 2 are therefore: $600 \mathrm{M}$ (amount sent to the Receiver) $300 \mathrm{M}$ (amount sent back by the Receiver) $=300 \mathrm{M}$

You are in the role of a Receiver. The Sender has chosen to send $400 \mathrm{M}$ to you. Hence, you could send back between 0 and $1200 \mathrm{M}(=3 \times 400 \mathrm{M})$ to the Sender. You have chosen to send back $100 \mathrm{M}$ to the Sender.

- Your earnings in part 2 are therefore: $1100 \mathrm{M}=1200 \mathrm{M}$ (the amount you received) - $100 \mathrm{M}$ (the amount you sent back).

- The earnings of the Sender in part 2 are therefore : $100 \mathrm{M}=400-400+100=100 \mathrm{M}$ Practice exercise. 
- You are in the role of a Sender. You have chosen to send 100 M to the Receiver. The Receiver has chosen to send back $0 \mathrm{M}$ to you.

Your earnings in part 4 are: The earnings of the Receiver in part 4 are:

- You are in the role of a Receiver. The Sender has chosen to send $300 \mathrm{M}$ to you. You have chosen to send back $100 \mathrm{M}$ to the Sender.

Your earnings in part 2 are:

The earnings of the Sender in part 2 are:

To make your decisions, right click here and open a new tab.

\section{Decision as Sender}

1. Mark how much you will like to send the receiver. (in multiples of $50 \mathrm{M}$ )

2. How much you expect the receiver to return you back if you send him 100 M (i.e. Receiver receives $300 \mathrm{M}$ ). If your prediction matches the actual decision of the matched receiver then you will win a bonus of $100 \mathrm{M}$. While making your decision choose between 0,100, 200 or 300 only. (Please mention in multiples of $50 \mathrm{M}$ )

3. How much you expect the receiver to return you back if you send him 200 M (i.e. Receiver receives $600 \mathrm{M}$ ). If your prediction matches the actual decision of the matched receiver then you will win a bonus of $100 \mathrm{M}$. While making your decision choose between 0,100, 200, 300, 400, 500 or 600 only. (Please mention in multiples of $50 \mathrm{M}$ )

4. How much you expect the receiver to return you back if you send him 300 M (i.e. Receiver receives $900 \mathrm{M}$ ). If your prediction matches the actual decision of the matched receiver then you will win a bonus of $100 \mathrm{M}$. While making your decision choose between 0,100, 200, 300, 400, 500, 600, 700, 800 and 900 only. (Please mention in multiples of $50 \mathrm{M}$ )

5. How much you expect the receiver to return you back if you send him $400 \mathrm{M}$ (i.e. Receiver receives $1200 \mathrm{M}$ ). If your prediction matches the actual decision of the matched receiver then you will win a bonus of $100 \mathrm{M}$. While making your decision choose between 0,100, 200, 300, 400, 500, 600, 700, 800, 900 1000, 1100 or 1200 only. (Please mention in multiples of $50 \mathrm{M}$ )

\section{Decision as Receiver}

1. Mark how much you will like to send back to the sender if you received $150 \mathrm{M}$ ( i.e. the sender sent you $50 \mathrm{M}$ ). Choose between 0 and 150 but in multiples of 50 only

2. Mark how much you will like to send back to the sender if you received $300 \mathrm{M}$ ( i.e. the sender sent you $100 \mathrm{M}$ ). Choose between 0 and 300 but in multiples of 50 only

3. Mark how much you will like to send back to the sender if you received $450 \mathrm{M}$ ( i.e. the sender sent you $100 \mathrm{M}$ ). Choose between 0 and 450 but in multiples of 50 only

4. Mark how much you will like to send back to the sender if you received $600 \mathrm{M}$ ( i.e. the sender sent you $200 \mathrm{M}$ ). Choose between 0 and 600 but in multiples of 50 only

5. Mark how much you will like to send back to the sender if you received $750 \mathrm{M}$ ( i.e. the sender sent you $100 \mathrm{M}$ ). Choose between 0 and 300 but in multiples of 50 only

6. Mark how much you will like to send back to the sender if you received $900 \mathrm{M}$ ( i.e. the sender sent you $300 \mathrm{M}$ ). Choose between 0 and 900 but in multiples of 50 only.

7. Mark how much you will like to send back to the sender if you received $1150 \mathrm{M}$ ( i.e. the sender sent you $100 \mathrm{M}$ ). Choose between 0 and 300 but in multiples of 50 only

8. Mark how much you will like to send back to the sender if you received 1200 M ( i.e. the sender sent you $400 \mathrm{M}$ ). Choose between 0 and 1200 but in multiples of 50 only.

Now we will randomly determining your role and determine your earnings. Coin toss for Role determination. Heads $:=$ you will be paid for Part 1 and Tails:= you will be paid for Part 2 . We will toss once more if you get Part 2 in the first toss in order to determine the roles.

We have come to the end of the experiment. Please fill out the exit survey. 


\subsection{Exit Survey}

1. Identity Number

2. Generally speaking, would you say that most people can be trusted or that you need to be very careful in dealing with people? (Code one answer):

(a) Most people can be trusted

(b) Need to be very careful

3. Do you think most people would try to take advantage of you if they got the chance, or would they try to be fair?

(a) Most of the time they would try to be fair

(b) Most of the time they would try to take advantage

4. Would you say that most of the time people try to be helpful, or that they are mostly just looking out for themselves?

(a) Most of the time people are helpful

(b) Most of the time they are just looking out for themselves

5. Suppose you left your wallet with Rs. 500 in the Metro. On a scale of 1 to 10, how much do you think are the chances that you will get it back?

6. How much you trust people from various groups. Could you tell me for each whether you trust people from this group completely, somewhat, not very much or not at all?
(a) Your family
(b) Your neighborhood
(c) People you know personally
(d) People you meet for the first time
(e) People of another religion
(f) People of another caste
(g) People of another nationality

7. How widespread do you think bribe taking and corruption is in this country?

(a) Almost no Public Officials are engaged in it

(b) A few Public Officials are engaged in it

(c) Most Public Officials are engaged in it

(d) Almost all Public Officials are engaged in it

8. Please mention for each of the following actions whether you think it can always be justified, never be justified, or something in between. 1 : Never justified 10: Justifiable 
(a) Claiming government benefits to which you are not entitled

(b) Avoiding a fare on public transport

(c) Cheating on taxes if you have a chance

(d) Someone accepting a bribe in the course of their duties

9. How do you see yourself: are you generally a person who is fully prepared to take risks or do you try to avoid taking risks? Please tick a box on the scale, where the value 0 means: "not at all willing to take risks' and the value 10 means: 'very willing to take risks'.

10. How do you see yourself: are you a person who is fully prepared to take risks when it comes to car driving/motorcycle riding etc. or do you try to avoid taking risks? Please tick a box on the scale, where the value 0means: 'not at all willing to take risks' and the value 10 means: 'very willing to take risks'.

11. How do you see yourself: are you a person who is fully prepared to take risks when it comes to financial matters or do you try to avoid taking risks? Please tick a box on the scale, where the value 0means: 'not at all willing to take risks' and the value 10 means: 'very willing to take risks'.

12. How do you see yourself: are you a person who is fully prepared to take risks when it comes to sports or leisure activities or do you try to avoid taking risks? Please tick a box on the scale, where the value 0 means: 'not at all willing to take risks' and the value 10 means: 'very willing to take risks'.

13. How do you see yourself: are you a person who is fully prepared to take risks when it comes to career or do you try to avoid taking risks? Please tick a box on the scale, where the value 0 means: 'not at all willing to take risks' and the value 10 means: 'very willing to take risks'.

14. How do you see yourself: are you a person who is fully prepared to take risks when it comes to health matters or do you try to avoid taking risks?Please tick a box on the scale, where the value 0 means: 'not at all willing to take risks' and the value 10 means: 'very willing to take risks'.

15. A short survey about yourself

(a) Sex
i. Male
ii. Female

(b) Age

(c) Are you the only child of your parents?

i. Yes

ii. No

(d) Ancestral State

(e) Mother Tongue

(f) Political Identity 
(g) Total Gross Family Income

(h) Caste Affiliation

(i) Religous Affiliation

(j) Religiosity - Not Religious (1) ... Strongly Religious (4)

(k) Your secondary level exam score was (in \%)

(l) Your higher secondary level exam score was (in \%)

(m) Your CAT/GMAT score (in percentile)

(n) Were the instructions clear? Please write a line or two.

(o) What strategies did you use?Please write a line or two.

(p) How did you decide on the strategies that you chose? Please write a line or two.

(q) What do you think this experiment was about? Please write a line or two. 